\title{
Absorbance based water quality indicators as parameters for treatment process control with respect to organic substance removal
}

\author{
Stawomir Szerzyna ${ }^{1,{ }^{*}}$, Marek Mołczan ${ }^{1,2}$, Matgorzata Wolska ${ }^{1,2}$, Wojciech Adamski ${ }^{1}$, \\ and Jacek Wiśniewski ${ }^{1}$ \\ ${ }^{1}$ Faculty of Environmental Engineering, Wrocław University of Science and Technology, Wyb. \\ Wyspiańskiego 27, 50-370 Wrocław \\ ${ }^{2}$ Wroclaw Municipal Water and Sewage Company, New Technologies Center, Na Grobli 14/16, \\ 50-421 Wrocław
}

\begin{abstract}
The dependence between individual water quality indicators and the UV254 was presented in the paper. Derived dependences allow to calculate values for these indicators using only the absorbance measurement, which could be easily on-line monitored. This approach make possible to reduce number of performed laboratory analyzes, used for the efficient controlling of water purification process. Identified relations are not universally applicable even for individual specific water source. These could be described with sufficient precise only for water samples from particular treatment step. Presented methodology can be helpful for exploitation of real water treatment systems to quick and efficient evaluation of individual purifying processes.
\end{abstract}

\section{Introduction}

The presence of organic substances in water for human consumption and the possibility of removing organic matter in unit water treatment processes has been the object of studies worldwide for many years [1-5]. Due to possibility of generation of organic substances harmful to human health in unit processes [6-7], especially during the disinfection process, it is necessary to ensure a most effective elimination of organic substances during water treatment. The amount and type of generated disinfection by-products (DBPs) depends on the types and properties of natural organic matter present in treated water. One of key parameters deciding the potential for forming chlorinated organic compounds is the molecular mass of the particle [8-11]. Studies [8] have shown that DBPs generation is determined also by dissolved organic carbon (DOC) content and UV absorbance at $254 \mathrm{~nm}$ wavelength values $\left(\mathrm{UV}_{254}\right)$ as a measure of aromatic substance content. UV absorbance measurements are used to evaluate chlorinated organic substance precursor content [12]. According to Korshin et al. [13], these precursors exhibit a much greater correlation with

\footnotetext{
${ }^{*}$ Corresponding author: slawomir.szerzyna@pwr.edu.pl
} 
absorbance at a wavelength of $272 \mathrm{~nm}\left(\mathrm{UV}_{272}\right)$ than at $254 \mathrm{~nm}$. Uyak and Demirbas [14] have also shown that the amount of trihalomethanes (THM) and choloroorganic acids generated are dependent on absorbance at a wavelength of $272 \mathrm{~nm}$, and specifically its decrease during unit water treatment processes. Lobanga et al. [15] utilized UV absorbance measurements at various wavelengths for an evaluation of susceptibility of organic substances contained in surface waters in South Africa to adsorption on granulated activated carbon. Apart from chlorinated organic substance precursors, UV absorbance values correlated with the content of substances, mainly humic and fulvic acids, which cause natural yellow-brown color of water [16].

UV absorbance measurements are very significant with regards to operating water treatment process systems. They yield knowledge concerning aromatic substance content and their susceptibility to removal using commonly-used unit processes. The wide spread nature of indicators based on UV absorbance stem from the simplicity of this measurement and the fact that frequently it supplements or replaces more advanced analytical methods, i.e. chromatography or DOC analysis.

This paper presents the variability in indicators based on UV and visible light absorbance measurements in surface water as supplied and after water treatment unit processes, and their relationship with other water contamination indices. The aim of these studies was evaluating the possibility of controlling a water treatment system by absorbance measurements, therefore avoiding the time lag in the case of a decrease in raw water quality.

\section{Study methodology}

The study was conducted at a research station operating two water treatment lines, each with a throughput of $3 \mathrm{~m}^{3} / \mathrm{h}$ that filter water from the Olawa river. Water samples for analysis were taken during 16 months of treatment line operation, at the inlet to both lines and after each unit process (raw water- R, water after coagulation and sedimentation- CS, water after sand filtration- SF, water after absorption on activated carbon - AC). The samples were taken once a day five days a week. The organic substance content was determined for the samples by the use of the following indicators: UV absorbance at wavelengths of 254 and $272 \mathrm{~nm}$, visible light color intensity at wavelengths of 340 (B340) and $410 \mathrm{~nm}$ (B410), total organic carbon (TOC) and dissolved organic carbon. Additionally, for all water samples, $\mathrm{pH}$, conductivity, temperature, alkalinity, turbidity, ammonia, nitrite and nitrate nitrogen concentrations, phosphate, sulfate, chloride, iron, manganese, aluminum and dissolved oxygen concentrations were measured, the results of which are not presented in this paper. All analysis was performed according to current applicable standards.

Total and dissolved organic carbon analysis was performed with a Shimadzu TOC-L analyzer, while absorbance and color intensity measurements were performed with a Shimadzu UV-1800 spectrophotometer.

\section{Discussion of results}

During the study period, the input water and the water after each of the unit processes was characterized by a large variability in composition (Table 1), which allowed for a certain generalization of the relationships that have been obtained. Because the study was conducted with various input water temperatures $\left(4.4-25.7{ }^{\circ} \mathrm{C}\right)$, this factor, which influences the intensity and type of transformations during the water treatment process, was also taken into account. The study results have confirmed the existence of a correlation 
between the $\mathrm{UV}_{254}$ absorbance values and other indicators of organic substance water contamination. Fig. 1. presents the dependence of $\mathrm{UV}_{272}$ absorbance on $\mathrm{UV}_{254}$ absorbance for water taken from different locations in the water treatment line.

Table 1. Value ranges analysed water quality parameters.

\begin{tabular}{|l|c|c|c|c|}
\hline & $\mathrm{R}$ & $\mathrm{CS}$ & $\mathrm{SF}$ & $\mathrm{AD}$ \\
\hline Temperature, ${ }^{\circ} \mathrm{C}$ & $4.4 \div 25.7$ & $4.8 \div 25.6$ & $5.2 \div 25.8$ & $6.1 \div 25.8$ \\
\hline $\mathrm{pH}$ & $6.68 \div 8.41$ & $6.63 \div 8.13$ & $6.43 \div 8.06$ & $6.32 \div 10.1$ \\
\hline Conductivity, $\mu \mathrm{S} / \mathrm{cm}$ & $288 \div 738$ & $292 \div 746$ & $293 \div 795$ & $299 \div 750$ \\
\hline Alkalinity, val $/ \mathrm{m}^{3}$ & $2.16 \div 3.58$ & $1.79 \div 3.49$ & $1.76 \div 3.40$ & $1.86 \div 3.34$ \\
\hline Turbidity, $\mathrm{NTU}$ & $2.6 \div 28.6$ & $0.3 \div 14.3$ & $0.0 \div 3.4$ & $0.0 \div 4.2$ \\
\hline Oxygen, $\mathrm{gO}_{2} / \mathrm{m}^{3}$ & $1.31 \div 12.21$ & $3.24 \div 12.32$ & $2.65 \div 12.10$ & $2.37 \div 11.53$ \\
\hline $\mathrm{UV}_{254}, \mathrm{~m}^{-1}$ & $6.08 \div 14.87$ & $3.86 \div 13.55$ & $3.76 \div 11.98$ & $0.44 \div 8.04$ \\
\hline $\mathrm{UV}_{272}, \mathrm{~m}^{-1}$ & $5.19 \div 11.95$ & $3.28 \div 10.95$ & $3.06 \div 9.68$ & $0.36 \div 6.39$ \\
\hline Color at $340 \mathrm{~nm}, \mathrm{~g} / \mathrm{m}^{3}$ & $5.70 \div 14.46$ & $3.02 \div 12.75$ & $2.73 \div 11.08$ & $0.37 \div 6.39$ \\
\hline Color at $410 \mathrm{~nm}, \mathrm{~g} / \mathrm{m}^{3}$ & $7.82 \div 24.62$ & $2.52 \div 20.24$ & $2.36 \div 18.31$ & $0.32 \div 8.18$ \\
\hline TOC, $\mathrm{gC} / \mathrm{m}^{3}$ & $3.23 \div 5.90$ & $2.71 \div 5.69$ & $2.30 \div 5.22$ & $0.98 \div 4.05$ \\
\hline DOC, $\mathrm{gC} / \mathrm{m}^{3}$ & $3.21 \div 5.68$ & $2.42 \div 5.45$ & $2.47 \div 5.03$ & $0.93 \div 4.01$ \\
\hline
\end{tabular}

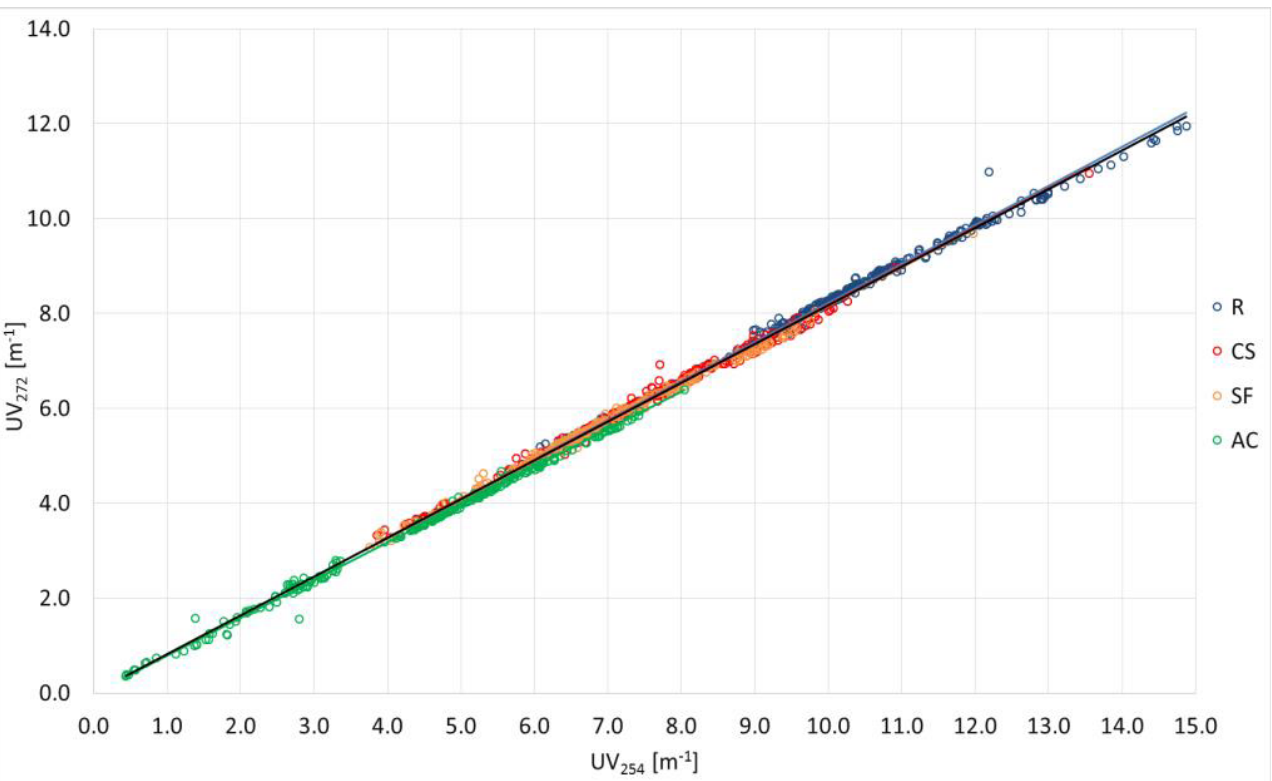

Fig. 1. Correlation between $\mathrm{UV}_{272}$ absorbance and $\mathrm{UV}_{254}$ absorbance for water after different unit treatment processes.

Analyzing the relationships that were obtained it may be concluded that the correlation between the two types of UV absorbance is linear regardless of the measured water origin. The directional coefficients of equations (1-4) obtained for waters after the different unit processes do not show significant differences:

$$
\text { Raw water: } y=0.822 x
$$

Water after coagulation and sedimentation: $y=0.8185 x$

Water after rapid filtration : $y=0.8158 x$ 


$$
\text { Water after adsorption: } y=0.7941 x
$$

The coefficients of determination $\mathrm{R}^{2}$ for the presented equations are in the range of 0.9923 to 0.9964 . The individual equations may be replaced by one general equation (5), which describes the relationship between $\mathrm{UV}_{272}$ absorbance and $\mathrm{UV}_{254}$ absorbance in the entire range studied of these indicators, for all types of water

$$
y=0.8173 x
$$

with also very good fit to the linear model $\left(\mathrm{R}^{2}=0.9976\right)$.

As reported in literature [16], both absorbance at $272 \mathrm{~nm}$ as well as at $254 \mathrm{~nm}$ are a measure of chlorinated disinfection by-product precursor content. This is also confirmed by the linear correlation found independent of water type, and similar directional coefficient values indicate a measurement of organic substances of similar properties. The obtained results (Fig.1) indicate a large utility of the coagulation and sedimentation process (removal effectiveness of $U_{254} 11-47 \%$ and $U_{272} 11-44 \%$ ) and adsorption (removal effectiveness of $\mathrm{UV}_{254} 18-99 \%$ and $\mathrm{UV}_{272} 18-99 \%$ ) in removing these contaminants. Low values of the $\mathrm{UV}_{254}$ and $\mathrm{UV}_{272}$ reduction effectiveness results from adsorption with saturated active carbon and high values results from adsorption with virgin active carbon.

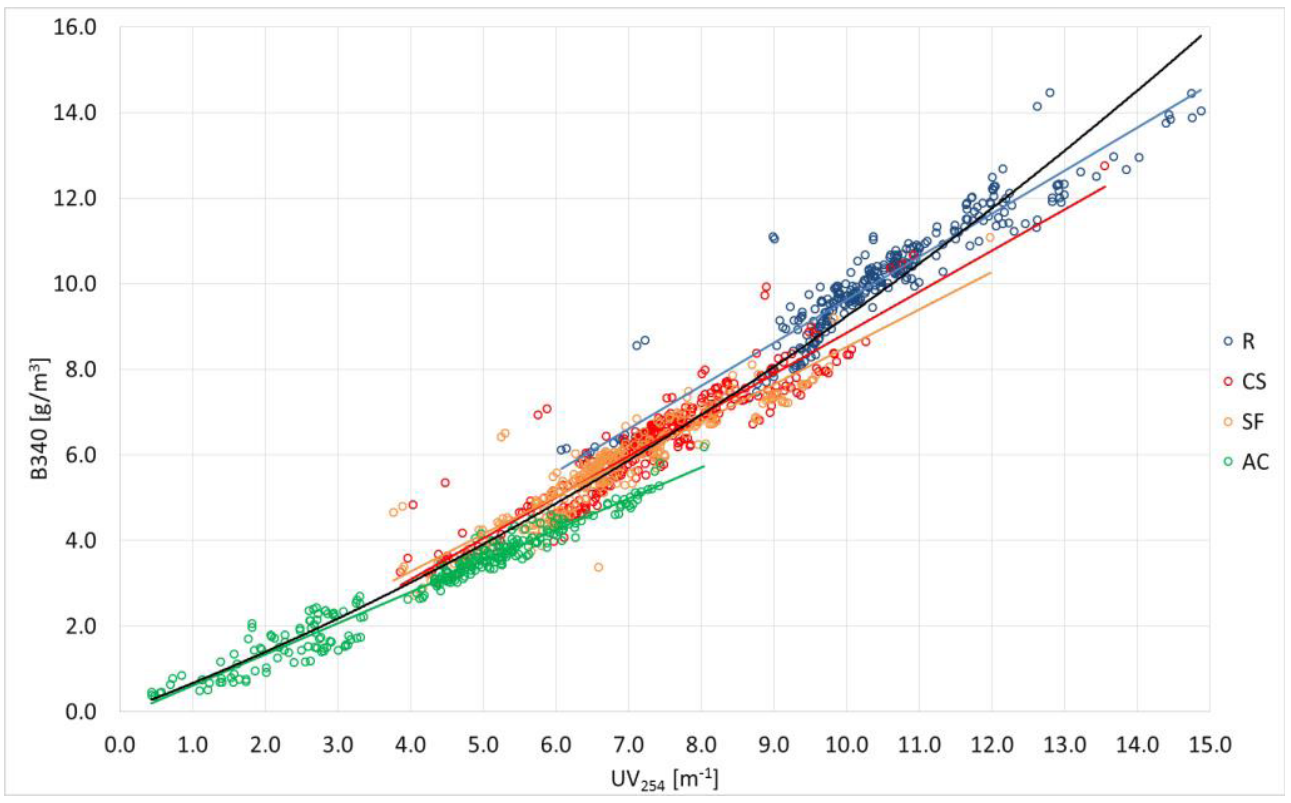

Fig. 2. Correlation between $340 \mathrm{~nm}$ values color and $\mathrm{UV}_{254}$ absorbance for water after different unit processes.

The correlation between color at $340 \mathrm{~nm}$ and absorption at $254 \mathrm{~nm}$ is shown in Fig. 2. This indicates a relationship between refractive substance content (evaluated via absorbance at $254 \mathrm{~nm}$ ) and the concentrations organic substances responsible for the color of water. From the presented correlation after subsequent unit processes it may be concluded that the greatest lowering of the values of these indicators took place during coagulation and, to a lesser degree, during adsorption. In the range of individual water types, the dependence between these two water quality indicators may be described by linear equations (6-9) with directional coefficients differing more than in the case of $U_{254}$ and $\mathrm{UV}_{272}$. $\mathrm{R}^{2}$ for these equation is in the range of $0.8611-0.9579$. 


$$
\text { Raw water: } y=1.0045 x-0.4164
$$

Water after coagulation and sedimentation: $y=0.9608 x-0.7501$

$$
\text { Water after rapid filtration : } y=0.875 x-0.2315
$$

Water after adsorption: $y=0.7271 x-0.1113$

Knowing the origin of studied water, with the use of these equations it is possible to relatively precisely calculate the color value at $340 \mathrm{~nm}$ based on $\mathrm{UV}_{254}$ absorbance. If the origin of the water is not known, a correlation in polynomial form may be used (see comment above):

$$
y=0.0282 x^{2}+0.6421 x
$$

The dependency of color at $410 \mathrm{~nm}$ on $\mathrm{UV}_{254}$ absorbance (fig. 3.), similarly as in the case of color at $340 \mathrm{~nm}$ and $\mathrm{UV}_{254}$ may be described by a linear equation only in the range of values obtained for the individual water types:

$$
\text { Raw water: } y=1.7633 x-1.7494
$$

Water after coagulation and sedimentation: $y=1.6222 x-3.0607$

$$
\text { Water after rapid filtration : } y=1.3174 x-1.1816
$$

Water after adsorption: $y=0.7514 x+0.0551$

In this case, these equations are less precise than in the case of the relationship between color at $340 \mathrm{~nm}$ and $\mathrm{UV}_{254}$ absorbance $\left(\mathrm{R}^{2}\right.$ in the range of 0.5822 to 0.6899$)$ with the best correlation found for water taken after the last treatment step ( $\mathrm{AC}-\mathrm{R}^{2}$ equal to 0.6899).

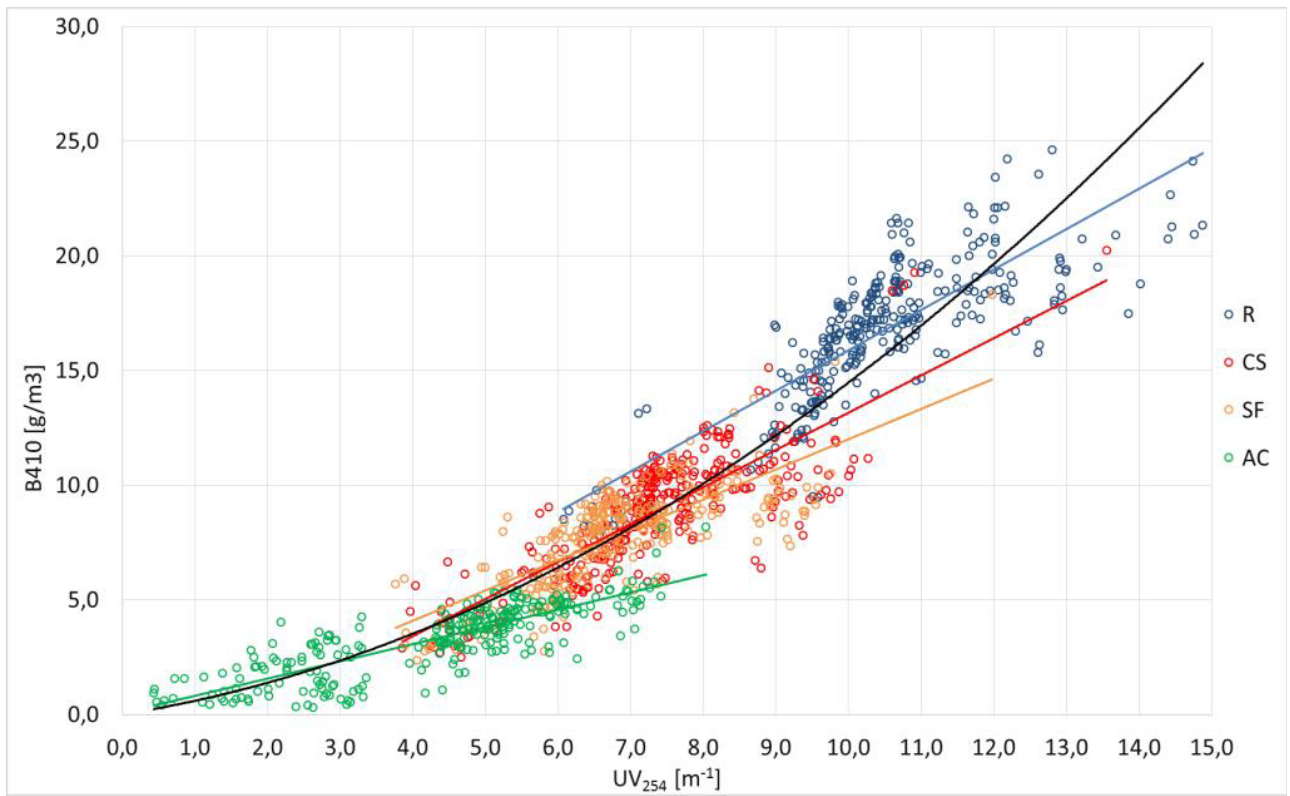

Fig. 3. Correlation between $410 \mathrm{~nm}$ values of color and $\mathrm{UV}_{254}$ absorbance for waters after different unit treatment processes. 
The differences found between the values of determination coefficients may testify to slightly different properties of organic substances as measured by absorbance at $340 \mathrm{~nm}$ and $410 \mathrm{~nm}$. A general equation describing the relationship of color at $410 \mathrm{~nm}$ and $U_{254}$, absorbance, regardless on the measured water type, which describes this relationship more precisely ( $\mathrm{R} 2$ equal to 0.8801 ) is presented below.

$$
y=0.0947 x^{2}+0.5009 x
$$

Correlations of total organic carbon and dissolved organic carbon to $\mathrm{UV}_{254}$ absorbance are presented in two subsequent figures (figs. 4 and 5). Both cases are best described by general equations which do not take into account the type of water measured. The correlation between total organic carbon and $\mathrm{UV}_{254}$ absorbance is described by equation 16 , while equation 17 describes this relationship for dissolved organic carbon:

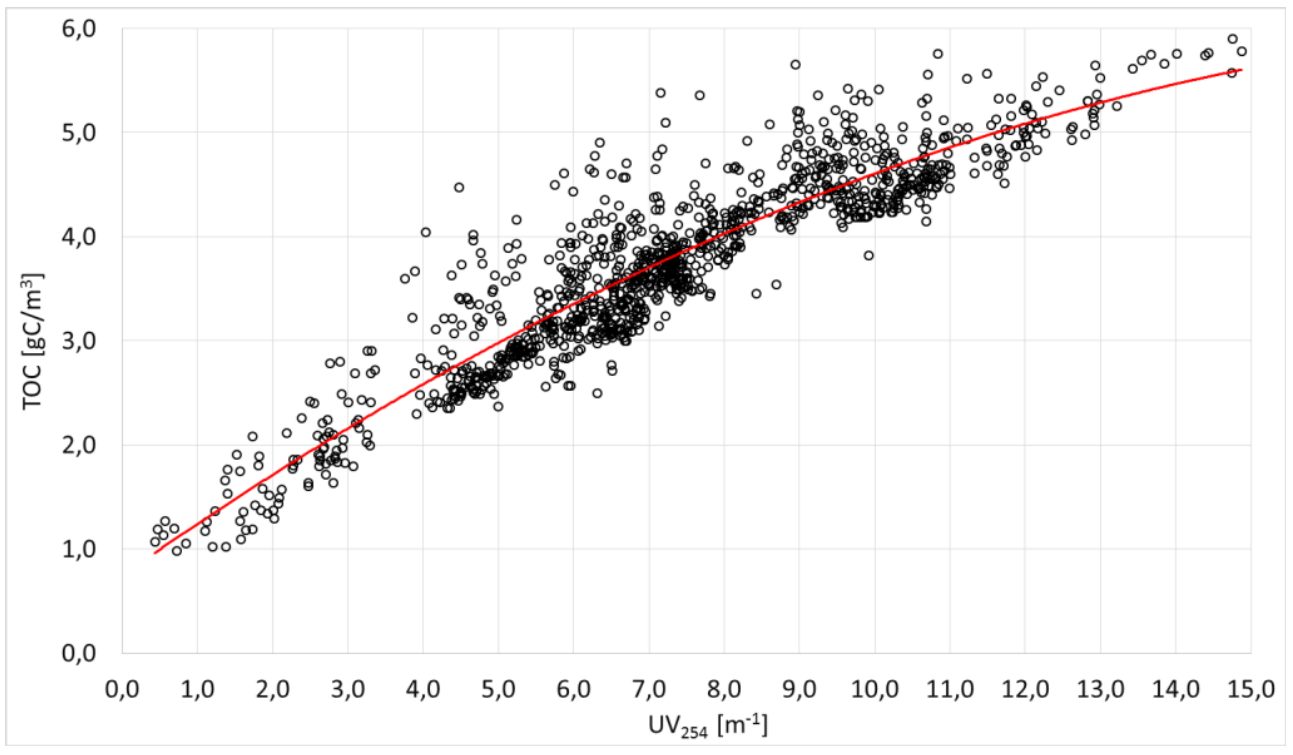

Fig. 4. Relationship between total organic carbon and $\mathrm{UV}_{254}$ absorbance at all water treatment stages.

$$
\begin{aligned}
& y=-0.0122 x^{2}+0.5082 x+0.745 \\
& y=-0.0074 x^{2}+0.4258 x+0.9228
\end{aligned}
$$

Both equations describe these relationship relatively precisely $\left(\mathrm{R}^{2}\right.$ determination coefficients of 0.8482 and 0.8718 respectively). These equations allow for replacing timeconsuming organic carbon analysis in treated water by values obtained through calculation. Consequently, these calculation may be utilized for an initial evaluation of the potential of organic substances to be removed by individual unit processes and the choice of process parameters, eg. reagent dosages. However, this requires an analysis of the relationships between changes in these parameters in unit processes. 


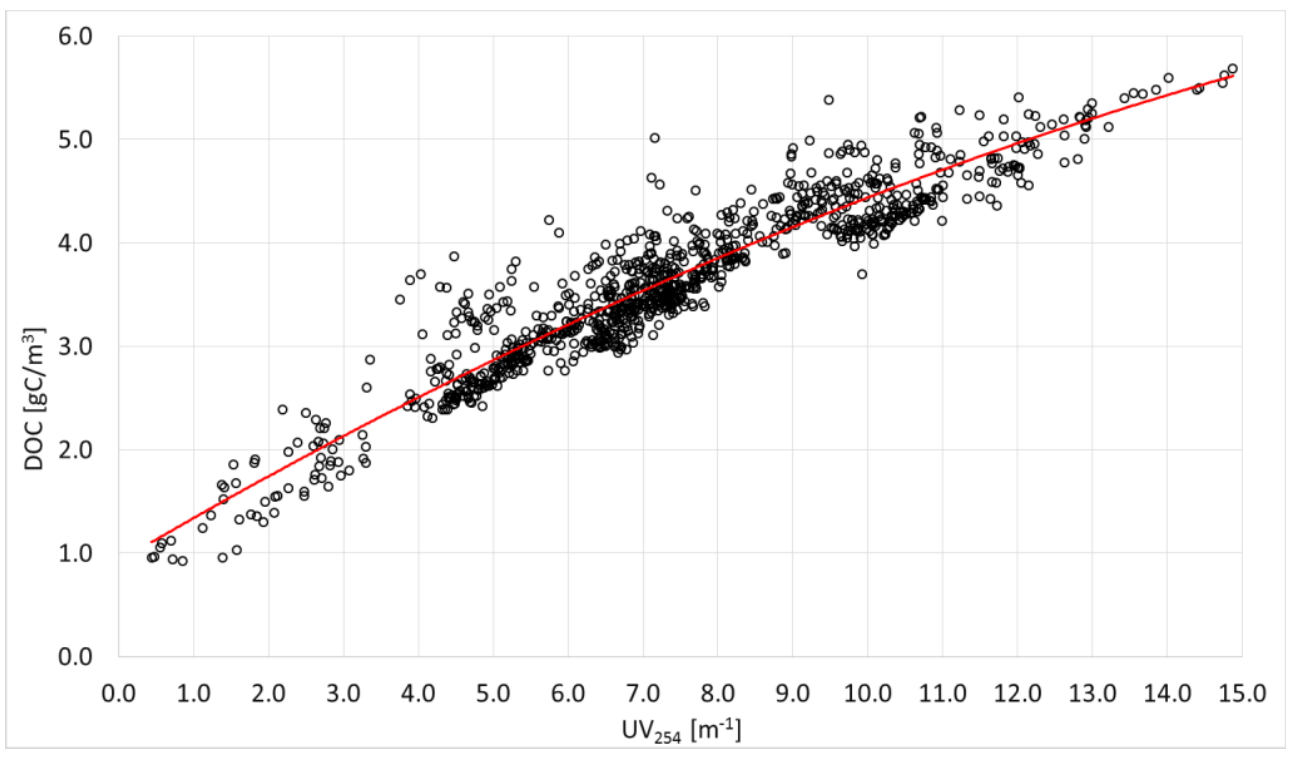

Fig. 5. Relationship between dissolved organic carbon and $\mathrm{UV}_{254}$ absorbance at all water treatment stages.

\section{Conclusion}

All the presented indicators of organic substance content correlate with ultraviolet absorbance at $254 \mathrm{~nm}$. A linear correlation was found for the relationship between absorbance at $\mathrm{UV}_{272}$ and $\mathrm{UV}_{254}$. In the case of the correlation between colors at $340 \mathrm{~nm}$ and $410 \mathrm{~nm}$, total organic carbon and dissolved organic carbon the general equations describing the correlation were of polynomial form. The equations determined in this study may serve to calculate values of remaining organic substance content indicators based only on $\mathrm{UV}_{254}$ measurements. This allows to obtain information about water quality very quickly, without the need to perform more time-consuming and specialized analysis, which is particularly useful for personnel controlling flow-type water treatment processes. Furthermore, if the treatment system has on-line type absorbance sensors, then the values from these sensors may be utilized for real-time calculations of remaining organic contamination indicators. This is particularly important if total organic carbon or dissolved organic carbon values, whose measurement are time-consuming, are used for controlling or on-going evaluation of treatment effectiveness. It must be remembered, however, that it is not possible to completely forego laboratory analysis, and the results from such analysis should be used for a continuous verification of the equations obtained.

This publication was made possible by the National Center for Research and Development grant (PBS3/B9/44/2015) "Research on effectiveness of new water treatment technology as a step towards a shift in thinking about water utility sector" (WODTECH), and thanks to involvement of both project consortium members (Wrocław Municipal Waterworks and Drainage Company and Wrocław University of Science and Technology). 


\section{References}

1. Z. Hasan, S. H. Jhung, J. Hazard. Mater. 283 (2015)

2. W. W. Tang, G. M. Zeng, J. L. Gong, J. Liang, P. Xu, C. Zhang, B. B. Huang, Sci. Total Environ. 468 (2014)

3. S. Metsämuuronen, M. Sillanpää, A. Bhatnagar, M. Mänttäri, Sep. Purif. Rev. 43 (1) (2014)

4. M. Inyang, E. Dickenson, Chemosphere 134 (2015)

5. A. Alsbaiee, B. J. Smith, L. Xiao, Y. Ling, D. E. Helbling, W. R. Dichtel, Nature 529 (2016)

6. R. Y. Yeh, M. J. Farré, D. Stalter, J. Y. Tang, J. Molendijk, B. I. Escher, Water Res. 59 (2014)

7. B. K. Mishra, S. K. Gupta, A. Sinha, Journal of Environmental Health Science and Engineering 12 (1), 73 (2014)

8. E. E. Chang, P. C. Chiang, H. J. Hsing, S. Y. Yeh, Toxic and Radioactive Waste Management (2007)

9. E.E. Chang, P.C. Chiang, W.Y.Tang, S.H. Chao,H.J. Hsing, Chemosphere 58 (2004)

10. J.D. Plummer, J.K. Edzwald, Water Sci. Technol. 35 (2001)

11. P.C. Chiang, E.E. Chang, C.H. Liang, Chemosphere 46 (2002)

12. J-B. Serodes, M. J. Rodriguez, H. Li, Ch. Bouchard, Chemosphere 51 (2003)

13. G. V. Korshin, W. W. Wu, M. M. Benjamin, O. Hemingway, Water Res. 36, 13 (2002)

14. V. Uyak, K. D. Demirbas, Environ. Forensics 15, 1 (2014)

15. K. P. Lobanga, J. Haarhoff, S. J. van Staden, Water SA 39, 3 (2013)

16. T. Thebe1, C. D. Swartz, I. R. Morrison, W. J. Engelbrecht, R. E. Loewenthal, P. Krüger, WISA 2000 Biennial Conference, Sun City, South Africa (2000) 